\title{
A direct comparison of the consequences of plant genotypic and species diversity on communities and ecosystem function
}

\author{
Susan C. Cook-Patton, ${ }^{1}$ Scott H. McArt,${ }^{2,3}$ Amy L. Parachnowitsch, ${ }^{1}$ Jennifer S. Thaler,,${ }^{1,2}$ \\ and Anurag A. Agrawal ${ }^{1,2}$ \\ ${ }^{1}$ Department of Ecology and Evolutionary Biology, Cornell University, Ithaca, New York 14853 USA \\ ${ }^{2}$ Department of Entomology, Cornell University, Ithaca, New York 14853 USA
}

\begin{abstract}
Biodiversity loss is proceeding at an unprecedented rate, yet we lack a thorough understanding of the consequences of losing diversity at different scales. While species diversity is known to impact community and ecosystem processes, genotypic diversity is assumed to have relatively smaller effects. Nonetheless, a few recent studies suggest that genotypic diversity may have quantitatively similar ecological consequences compared to species diversity. Here we show that increasing either genotypic diversity of common evening primrose (Oenothera biennis) or species diversity of old-field plant species resulted in nearly equivalent increases $(\sim 17 \%)$ in aboveground primary production. The predominant mechanism explaining this effect, niche complementarity, was similar for each type of diversity. Arthropod species richness also increased with both types of plant diversity, but the mechanisms leading to this effect differed: abundance-driven accumulation of arthropod species was important in plant genotypic polycultures, whereas resource specialization was important in plant species polycultures. Thus, similar increases in primary productivity differentially impacted higher trophic levels in response to each type of plant diversity. These results highlight important ecological similarities and differences between genotypic and species diversity and suggest that genotypic diversity may play a larger role in community and ecosystem processes than previously realized.
\end{abstract}

Key words: arthropods; biodiversity; common evening primrose; community genetics; eastern North America; ecosystem function; Oenothera biennis; old fields.

\section{INTRODUCTION}

Rapid human alterations of the environment are leading to substantial reductions in biodiversity (Pimm et al. 1995, Chapin et al. 2000). These changes may have profound consequences, as diverse systems can be more productive (Tilman et al. 1996, Cardinale et al. 2007), stable (Reusch et al. 2005, Tilman et al. 2006), and resistant to invasions (Levine 2000) than less diverse systems. While most biodiversity research has focused on species diversity, recent work has found that genotypic diversity within species can also have pronounced ecological consequences (Wimp et al. 2004, Hughes et al. 2008, Parker et al. 2010). However, to date, there has been no direct comparison of either the relative importance of genotypic and species diversity or the mechanisms by which genotypic and species diversity alter community structure and ecosystem functioning.

Greater productivity in diverse mixtures may be due to the increased probability of including a highly productive species (i.e., the sampling effect), dominance of highly productive species in polycultures (i.e., a

Manuscript received 20 May 2010; revised 27 September 2010; accepted 5 October 2010. Corresponding Editor: R. E. Irwin.

${ }^{3}$ Corresponding author. E-mail: shm33@cornell.edu positive selection effect), or reduced competition in polycultures due to niche partitioning or facilitation among the interacting species (i.e., positive complementarity) (Loreau and Hector 2001, Hooper et al. 2005). Niche partitioning, in particular, should be affected by trait variation and relatedness among interacting organisms (Petchey et al. 2004, Villeger et al. 2008, Cadotte et al. 2009, Hillebrand and Matthiessen 2009). Plant assemblages with greater trait variation are predicted to exhibit less niche overlap, more efficiently utilize resources, and achieve higher productivity than less variable assemblages (Cadotte et al. 2009, Hillebrand and Matthiessen 2009). Because trait variation within a single species is expected to be lower than trait variation among multiple species, one would predict that biomass increases in response to plant genotypic diversity would be less pronounced than that of species diversity. Despite these expectations, a few recent studies have suggested that plant genotypic diversity may have similar impacts to species diversity on biomass, fitness, and other ecosystem functions (Schweitzer et al. 2005, Crutsinger et al. 2006, Johnson et al. 2006). However, these studies did not manipulate plant genotypic and species diversity simultaneously.

Two alternative hypotheses predict how general patterns of arthropod community diversity will respond to plant diversity (for hypotheses addressing responses 
of specific trophic levels, see Root 1973, Barbosa et al. 2009.) The resource specialization hypothesis posits that because many arthropods specialize on distinct host plant species, increasing the number of plant species in a patch will attract a more diverse fauna (Hutchinson 1959, Strong et al. 1984). Alternatively, the more individuals hypothesis suggests that as available energy (e.g., plant biomass) increases, there will be a greater number of arthropod individuals present and thus a higher probability of observing more arthropod species (Srivastava and Lawton 1998). Because plant biomass is expected to increase with plant diversity, arthropod diversity is expected to also increase through abundance-driven accumulation of species. When considered in the context of plant trait variation, both of these hypotheses predict that the response of arthropods to plant species diversity will be greater than to plant genotypic diversity. In contrast, two recent studies have suggested that plant genotypic and species diversity may similarly impact the structure of higher trophic level communities (Crutsinger et al. 2006, Johnson et al. 2006).

In this study, we present the first direct comparison of the effects of plant genotypic and species diversity on arthropod species diversity and plant productivity (an ecosystem function) by simultaneously manipulating these two levels of diversity within a single field experiment.

\section{Materials and Methods}

\section{Study species and plant propagation}

We manipulated plant genotypic diversity with Oenothera biennis L. (common evening primrose, Onagraceae), a native herbaceous plant that is common to old fields and disturbed areas in eastern North America. Oenothera biennis reproduces via a permanent translocation heterozygosity mating system, which results in clonally related seeds (Cleland 1972) (i.e., all seeds produced by an individual plant are genetically identical to one another and the parent). Oenothera biennis genotypes vary from an annual to perennial lifehistory strategy that is known to plastically respond to the environment (Johnson 2007).

We collected $O$. biennis seeds from individual plants in 24 distinct populations around Ithaca, New York, USA. Each genotype used in this experiment was determined to be unique using nine polymorphic microsatellite loci specifically developed for $O$. biennis (Larson et al. 2008). To reduce maternal effects, we first grew the seeds in a common garden in 2007, which was sprayed with insecticide at regular intervals throughout the growing season, and we used seeds collected from these plants (24 genotypes) for our experiment.

We focus on comparing the effects of plant genotypic vs. species diversity exclusively (and not functional group diversity) because genotypic variation within a species presumably offers no functional group diversity. Thus, for the species treatments we did not have nitrogen-fixers in the species pool, because the presence of this functional group can overwhelm effects of richness (Hooper et al. 2005, Cadotte et al. 2009). We used 24 species that are common in old fields, co-occur with $O$. biennis, germinate easily, and do not possess particularly notable functional attributes: Carex sp. 1, Carex sp. 2, Cichorium intybus, Daucus carota, Dianthus armeria, Dipsacus sativus, Elymus repens, Epilobium parviflorum, Galium mollugo, Leucanthemum vulgare, Pastinaca sativa, Penstemon digitalis, Phleum pratense, Plantago lanceolata, Rudbeckia hirta, Rumex crispus, Saponaria officinalis, Silene vulgaris, Solidago altissima, Symphyotrichum simplex, Symphyotrichum lateriflorum, Verbascum blattaria, Verbascum thapsus, and Verbena hastata. Seeds were collected from multiple individuals at three separate fields around Ithaca in 2007 and pooled to generate genetically diverse seed sources for each species. This species pool includes three annuals, six biennials, and 15 perennials (Appendix B: Table B1).

We cold-stratified $\left(4^{\circ} \mathrm{C}\right.$, four days) all seeds in April 2007, sowed them into 96-well trays filled with soil (Promix "BX" with biofungicide; Premier Tech Horticulture, Quakertown, Pennsylvania, USA), and thinned germinated seedlings to a single individual per well. Plants were watered ad libitum and fertilized weekly (21-5-20 NPK, $150 \mathrm{ppm}$ ) while in the greenhouse (14:10 hour light : dark cycle, five weeks) and then field-hardened in an outdoor mesh cage (one week) prior to planting in the field.

\section{Field establishment}

In late May 2008, we established the experiment in an abandoned agricultural field where the soil was plowed, but otherwise untreated. Using a substitutive design and our pools of $24 \mathrm{O}$. biennis genotypes and 24 old-field species, we constructed four treatments: genotypic monocultures ("GM," one O. biennis genotype), genotypic polycultures ("GP," eight $O$. biennis genotypes), species monocultures ("SM," multiple genotypes of a single species that did not include $O$. biennis), and species polycultures ("SP," eight species that did not include $O$. biennis). All plots contained eight equally spaced individuals arrayed in a ring $0.5 \mathrm{~m}$ in diameter. This density of plants is common in old-field plant communities and $O$. biennis populations (S. H. McArt and S. C. Cook-Patton, personal observations). The original design included 264 plots, but due to the loss of individuals within plots, we restricted our analyses to the 230 plots that experienced no mortality (GM, $n=46$; GP, $n=69 ; \mathrm{SM}, n=66$; and SP, $n=49)$. Every genotype or species appeared $\sim 20$ times in polyculture and 2-3 times in monoculture (except for two O. biennis genotypes that only had one monoculture each due to mortality and Verbascum thapsus, which had no monocultures due to mortality).

In addition to the ring of plants, we grew a single $O$. biennis focal plant in the middle of every plot to test how the diversity treatments impacted natural selection on $O$. 
biennis. We ensured that the focal plant was always a different genotype than the $O$. biennis ring plants. Thus, our treatments are balanced such that species "monocultures" always contained two species (eight plants of the same species in a ring and one $O$. biennis focal plant) and genotype "monocultures" always contained two genotypes (eight plants of the same O. biennis genotype in a ring and one $O$. biennis focal plant of a different genotype), while polycultures always contained nine genotypes or nine species. The natural selection data will be presented elsewhere, but here we include the focal plant in analyses for completeness and accuracy (see Plant analyses).

We separated plots by $1.5 \mathrm{~m}$ and clipped encroaching weeds by hand every 2-3 weeks to ensure treatments remained consistent throughout the summer. During the experiment, 18 of the 24 species bolted and flowered, and all of the O. biennis genotypes bolted and flowered. For O. biennis genotypes and plant species that bolted, nearly every individual plant bolted and bolting did not vary by diversity treatments $(O$. biennis genotypes, Pearson $\chi^{2}=0.06, P=0.80$; plant species, Pearson $\chi^{2}$ $=0.39, P=0.53$ ). Thus, diversity did not affect lifehistory expression of the plants.

\section{Plant analyses}

During the second and third weeks of October, we harvested the aboveground biomass of every plant, which was then dried $\left(65^{\circ} \mathrm{C}\right)$ and weighed to the nearest $0.1 \mathrm{~g}$. We analyzed plant productivity via a two-way analysis of variance with main effects of diversity level (monocultures or polycultures) and level of plant relatedness (genotypic or species), plus their interaction (JMP, version 7; SAS Institute, Cary, North Carolina, USA). An alternative approach is to view this experiment as four distinct treatments and conduct analyses via a one-way ANOVA, which we have also done to verify that all two-way ANOVA results were similar to one-way ANOVA results. To account for spatial heterogeneity in the field, we divided the experiment into six blocks, where each block contained equal proportions of the four treatments, and included block as a random effect in all analyses. We analyzed both the full plot data (the sum of eight ring plants plus the focal plant) as well as the ring data alone (sum of the eight ring plants) for all of our analyses. Excluding the focal plant from our analyses (i.e., analyzing only the ring plants) did not alter the direction or significance of any of our results. We present the full plot data because it includes all the interactions that occurred in the plot.

Loreau and Hector (2001) devised a method to partition diversity effects into complementarity and selection effects. We modified this technique slightly to account for the absence of true monocultures (due to the focal plant in the middle of the ring; see Table 1). Whether a genotype occurred in the center or the ring had a substantial effect. For example, a single, representative genotype produced, on average, $110 \mathrm{~g}$ biomass in the ring vs. $69 \mathrm{~g}$ as a focal plant. Thus, to determine the expected biomass of a ring plant in polyculture, we used the average value of an individual genotype or species from the monoculture ring. To determine the expected biomass of a focal plant, we took the average value of the two or three times that this genotype occurred in the middle of a genotypic monoculture (if calculating expected values for a genotypic polyculture) or a species monoculture (if calculating expected values for a species polyculture).

Complementarity is calculated as $N \Delta \bar{R} Y \bar{M}_{i}$ and selection as $N \operatorname{cov}(\Delta R Y, M)$. If we exclude the focal plant, the modification produces mathematically equivalent results to the original method and our results do not qualitatively change (see Appendix B). Note that one species, Verbascum thapsus, did not survive in monoculture, so the three monocultures and 10 species polycultures with this species were excluded from the complementarity and selection analyses.

To examine how competition intensity changed from monoculture to polyculture we calculated the corrected index of relative competition intensity (CRCI) (Oksanen et al. 2006). This index reduces bias inherent to other indices by extending the range of arguments in which the function behaves linearly. To minimize errors due to the aberrant behavior of individuals, we first calculated mean values of individual genotype or species performance in each treatment. We then calculated competition intensity as CRCI $=\operatorname{arc} \sin \left(\left(X_{\mathrm{r}}-X_{\mathrm{c}}\right) /\left(\max X_{\mathrm{r}}, X_{\mathrm{c}}\right)\right)$ (Oksanen et al. 2006) where $X_{\mathrm{r}}$ is the mean performance of a particular genotype or species in monoculture and $X_{\mathrm{c}}$ is the mean value in polyculture. Note that CRCI is unitless, and values further from 0 indicate greater differences in competition intensity between treatments.

\section{Arthropod analyses}

In mid-July and again in mid-August, we censused arthropods by visually surveying every plant in the experiment ( $N=2070$ plants). We identified familiar arthropods in the field or collected specimens of unknown arthropods for later identification. To identify arthropods, we consulted relevant literature and the expertise of E. R. Hoebeke. Arthropods were identified to the lowest taxonomic level possible, generally species or genus and occasionally family. We also assigned arthropods to a feeding guild (herbivore, predator, omnivore, or detritivore) based on relevant literature and the expertise of E. R. Hoebeke. We lumped together parasitoid species that were less than $3 \mathrm{~mm}$ in length $(n=$ 10) because of logistical difficulties associated with their field identification. We did not attempt to count or identify arthropods that were less than $1 \mathrm{~mm}$ in length (e.g., thrips, collembola).

Similar to the plant analyses, we used a two-way ANOVA with block as a random effect to test for the effects of plant diversity on cumulative arthropod abundance and richness. Repeated-measures analyses yielded qualitatively identical results to the cumulative 
TABLE 1. Loreau and Hector's methods (2001) were modified to accommodate the inclusion of a focal plant in our common-garden design.

\begin{tabular}{|c|c|}
\hline Abbreviation & Definition \\
\hline$M_{i}$ & $\begin{array}{l}\text { average yield of an individual from species or genotype } i \text { in the low-diversity treatment; for species this is } \\
\text { the average of all individuals in a ring; for genotypes this was either the average of all individuals in a } \\
\text { ring or of all individuals in the center of a genotypic or species monoculture }\end{array}$ \\
\hline$Y_{\mathrm{O} i}$ & observed yield of species $i$ or genotype $i$ in the polyculture \\
\hline$Y_{\mathrm{O}}=\Sigma_{i} Y_{\mathrm{O} i}$ & total observed yield of the polyculture \\
\hline $\mathrm{RY}_{\mathrm{E}}$ & $\begin{array}{l}\text { expected relative yield of species } i \text { or genotype } i \text { in a polyculture (which is } \mathbf{1} \text { because the yield is expected } \\
\text { to be identical to that in the monoculture) }\end{array}$ \\
\hline $\mathrm{RY}_{\mathrm{O} i}=Y_{\mathrm{O} i} / M_{i}$ & observed relative yield of species $i$ or genotype $i$ in the polyculture \\
\hline$Y_{\mathrm{E} i}=\mathrm{RY}_{\mathrm{E} i} M_{i}=M_{i}$ & expected yield of an individual from species or genotype $i$ in the polyculture \\
\hline $\begin{array}{l}Y_{\mathrm{E}}=\Sigma_{i} Y_{\mathrm{E} i} \\
\Delta Y=Y_{\mathrm{O}}-Y_{\mathrm{E}}\end{array}$ & $\begin{array}{l}\text { total expected yield of the polyculture } \\
\text { deviation from total expected vield in the polvculture }\end{array}$ \\
\hline$\underset{N}{\Delta \mathrm{RY}_{i}}=\mathrm{RY}_{\mathrm{O} i}-\mathrm{RY}_{\mathrm{E} i}$ & deviation from expected relative yield of species $i$ or genotype $i$ in the polyculture \\
\hline & number of species or genotypes in the polyculture \\
\hline
\end{tabular}

Note: Our changes are indicated in boldface, while the remainder of the text is replicated from the original paper.

data set, so we chose the latter to facilitate more sophisticated follow-up analyses. We used a $\log +1$ transformation on the abundance data to improve normality.

To test for the effect of plant biomass on arthropod abundance we divided arthropod abundance by the biomass of each plant and log-transformed the resulting data to improve normality. Division assumes a linear relationship between these two variables and indeed a linear function provided the best fit for the data $\left(R_{\text {lin }}^{2}=\right.$ $\left.0.40, R_{\log }^{2}=0.34\right)$. Next, because of the well-known nonlinear relationship between arthropod abundance and richness, we used individual-based rarefaction (Ecosim 7.0; Gotelli and Entsminger 2006) to test the effect of cumulative arthropod abundance on cumulative richness. We conducted rarefaction at each level of plant relatedness independently in order to compare arthropod communities drawn from the same distribution (Gotelli and Graves 1996). To test for differences in rarefied arthropod richness we used ANOVA with post hoc independent contrasts.

We visualized the similarity among arthropod assemblages on genotypes and species with nonmetric multidimensional scaling (NMDS, Vegan 1.15-1, R version 2.8.1; R Foundation for Statistical Computing, Vienna, Austria). The semimetric Bray-Curtis dissimilarity coefficient was used to compare arthropod assemblages on monocultures of $O$. biennis genotypes and plant species using a presence/absence data set. We then conducted 500 simulations on a random data set with identical parameters (McCune and Grace 2002) to verify that random stress (mean $=0.28$ ) was significantly higher than model stress (mean $=0.23$ ).

\section{Results}

We found an overall positive effect of diversity on plot-level plant productivity (diversity, $F_{1,221.4}=15.62$, $P=0.0001)$. Genotypic and species polycultures showed nearly equivalent increases in productivity (diversity $\times$ relatedness level, $F_{1,221.4}=1.84, P=0.18$ ): total biomass was $16.8 \%$ and $16.9 \%$ greater in genotypic and species polycultures than in monocultures, respectively (Fig. 1a). Analysis via one-way ANOVA produced similar results $\left(F_{3,221.3}=122.6, P<0.0001\right)$ : post hoc independent contrasts on plant biomass indicated that genotypic polycultures were more productive than genotypic monocultures $\left(F_{1,221.4}=14.0, P=0.0002\right)$ and that species polycultures were marginally more productive than species monocultures $\left(F_{1,221.1}=3.4, P=\right.$ 0.065). While selection effects were weak to negative (Fig. 1d), we found that complementarity among individuals contributed to the increases in plant productivity and did not differ between each level of relatedness $\left(F_{6,102}=1.06, P=0.39\right.$; Fig. $\left.1 \mathrm{~d}\right)$. Another metric more commonly employed in the plant competition literature, the corrected index of relative competition intensity (CRCI) (Oksanen et al. 2006), showed similar results: there were similar decreases in competition intensity with increasing plant diversity $(-0.79$ for genotypic diversity and -0.56 for species diversity, $F_{1,45}$ $=0.07, P=0.79$ ). Thus, our comparable changes in complementarity and competition intensity may explain the remarkably similar increases in plot-level productivity that we observed in both genotypic and species polycultures of plants.

To determine the effects of plant biodiversity on higher trophic-level communities, we nondestructively surveyed arthropods, which naturally recruited to each plant, twice during peak growing season. In total, we made 76753 observations of $\sim 252$ arthropod species. We found that arthropod richness increased with both types of plant diversity, but changed more dramatically in plant species polycultures (diversity $\times$ relatedness level, $F_{1,221.5}=10.96, P=0.001$; Fig. 2a). Predators showed the most pronounced response to plant diversity, increasing in abundance $80 \%$ in species polycultures and $30 \%$ in genotypic polycultures (diversity, $F_{1,221}=$ 18.62, $P<0.0001$; diversity $\times$ relatedness level, $F_{1,221.6}=$ 4.42, $P=0.037$; see Appendix A), while increasing in richness $54 \%$ and $17 \%$, respectively (diversity, $F_{1,221.3}=$ 17.92, $P<0.0001$; diversity $\times$ relatedness level, $F_{1,221.8}=$ 3.87, $P=0.051$; Fig. 2a). Herbivores increased in 

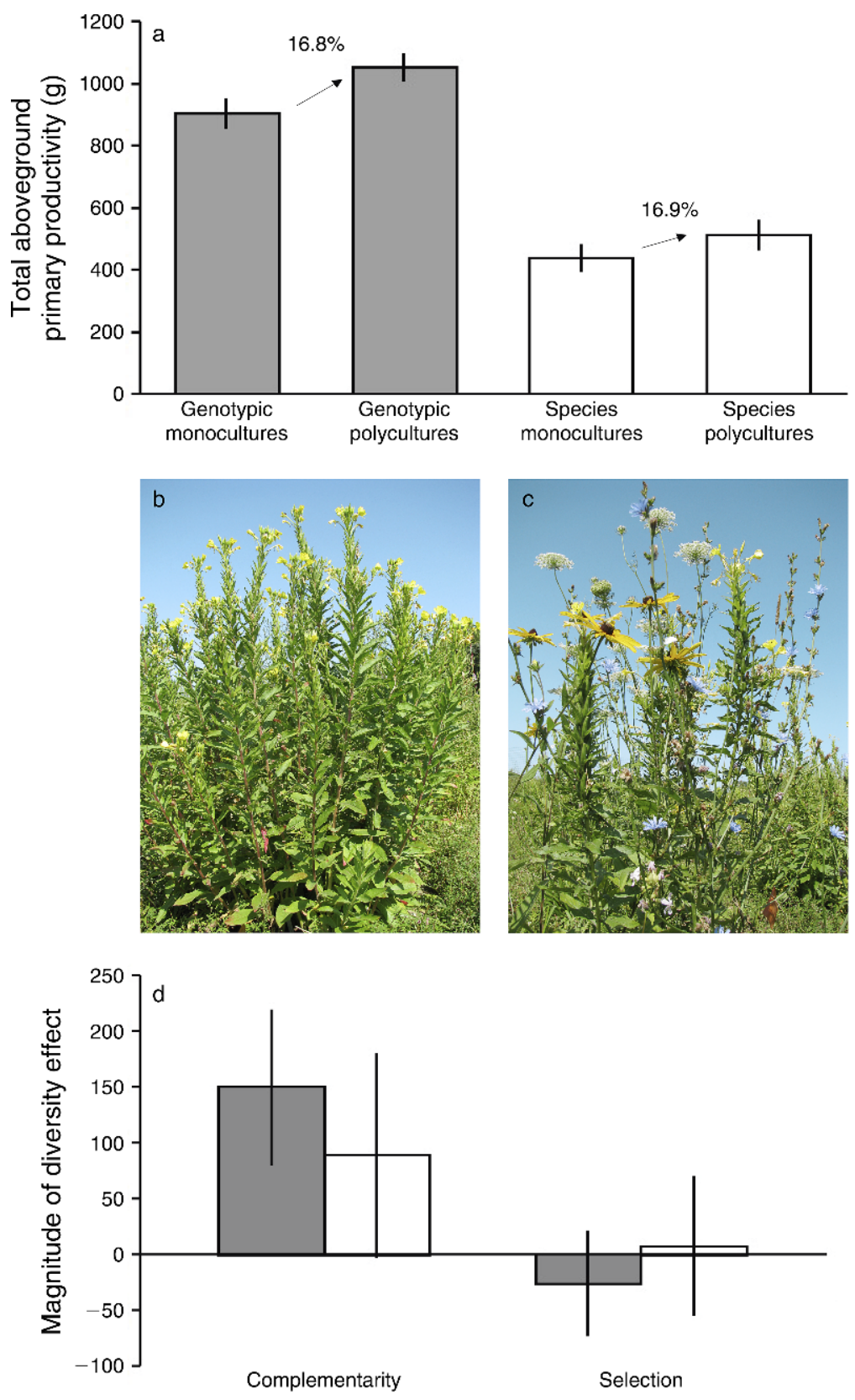

FIG. 1. Plant diversity effects on productivity. (a) Genotypic and species polycultures had $\sim 17 \%$ more biomass than their respective monocultures (least-square means \pm SE). Photographs of (b) genotypic polyculture and (c) species polyculture. (d) The overall diversity effect (means with 95\% CI) can be partitioned into complementarity or selection effects (Loreau and Hector 2001) for genotype polycultures (gray bars) and species polycultures (white bars). Positive complementarity indicates that, on average, species are more productive in polyculture than would be predicted by their monoculture values. Positive selection indicates that highly productive species are dominating the polycultures, whereas negative selection indicates that smaller species are showing a disproportionately large increase in polyculture. Mean diversity effects $\pm 95 \%$ CI are shown. Our study was conducted on seeds of common evening primrose (Oenothera biennis) and 24 other old-field species collected around Ithaca, New York, USA.

abundance $44 \%$ and $30 \%$ in plant species and genotypic polycultures (diversity, $F_{1,221}=8.54, P=0.004$; diversity $\times$ relatedness level, $F_{1,221.2}=0.007, P=0.93$; Appendix A), while increasing in richness $30 \%$ and $10 \%$, respectively (diversity, $F_{1,221.4}=28.76, P<0.0001$; diversity $\times$ relatedness level, $F_{1,220.9}=6.80, P=0.010$; Fig. 2a).
Omnivores and detritivores showed similar patterns of increases in abundance and richness at both levels of relatedness (Fig. 2a, Appendix A), although responses were not as pronounced. A one-way ANOVA approach to these analyses produced qualitatively identical results (not shown). 

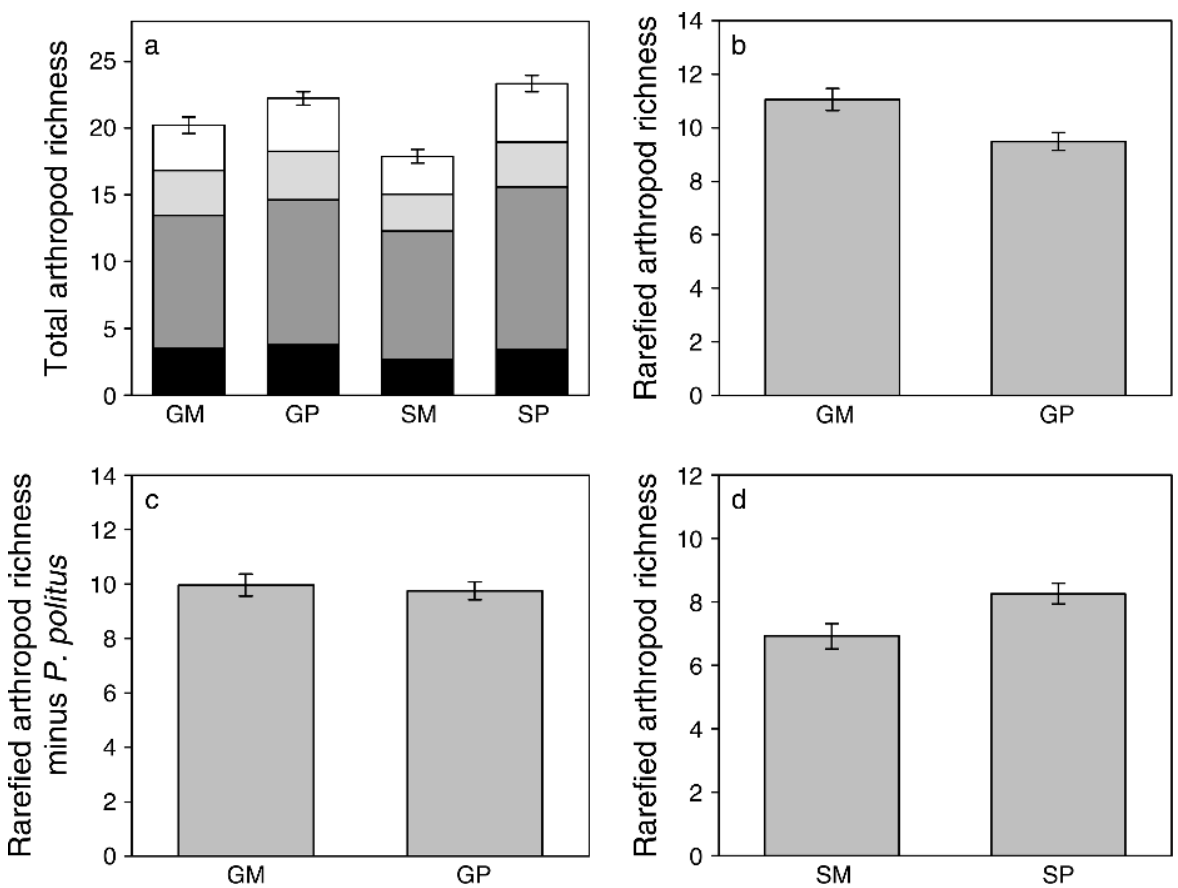

FIG. 2. Relationship between plant diversity and arthropod species richness. (a) Overall arthropod richness (least-square means $\pm \mathrm{SE}$ ), with (top to bottom) predators represented in white, omnivores in light gray, herbivores in dark gray, and detritivores in black. (b) Rarefied arthropod richness decreased with plant genotypic diversity (least-square means \pm SE). (c) After removing the dominant insect, Plagiognathus politus, from the data set (see Results), rarefied arthropod richness showed no change with plant genotypic diversity (least-square means $\pm \mathrm{SE}$ ). (d) Rarefied arthropod richness increased with plant species diversity (least-square means \pm SE). At each level of plant relatedness, we used individual-based rarefaction (Ecosim 7.0; Gotelli and Entsminger 2006) to test the effect of cumulative arthropod abundance on cumulative richness. To test for differences in rarefied arthropod richness, we used ANOVA with post hoc independent contrasts. Abbreviations are: GM, genotypic monocultures; GP, genotypic polycultures; SM, species monocultures; SP, species polycultures.

To further understand how plant diversity at each level of relatedness affected arthropod community structure, we first evaluated the influence of plant productivity on the number of arthropod individuals. After dividing arthropod abundance by plant biomass, the previously significant effect of plant diversity on arthropod abundance disappeared $\left(F_{1,221.6}=0.19, P=\right.$ 0.66). Thus, arthropod abundance at both levels of relatedness was largely controlled by plant productivity and not by plant diversity per se.

We next used rarefaction to determine whether increases in arthropod species richness would be best explained by arthropod abundance (more individuals hypothesis) or by arthropod specialization on distinct host plants (resource specialization hypothesis). Contrary to expectations, rarefied richness decreased with plant genotypic diversity (post hoc contrast, $F_{1,212}=$ $9.04, P=0.003$; Fig. 2b). This decrease in genotypic polycultures derives from a nonadditive increase in the abundance of a single dominant species, Plagiognathus politus (Miridae), resulting in a lower richness than expected for that insect abundance. Removing $P$. politus from the data set resulted in no difference in rarefied richness between treatments (Fig. 2c). Both of these results are consistent with greater arthropod abundances causing higher arthropod species richness in genotypic polycultures, supporting the more individuals hypothesis. Conversely, rarefied richness increased with plant species diversity (post hoc contrast, $\mathrm{F}_{1,212}=6.27, P=$ 0.01 ; Fig. 2d), indicating that the diversity of hostspecific resources was important for the increase in arthropod richness. This result, in addition to the fact that the arthropod communities found on each plant species were far more divergent than the arthropod communities on each plant genotype (nonparametric MANOVA, $F_{1,46}=6.78, P<0.0001$, Fig. 3), highlights the importance of resource specialization for the arthropod community response to plant species diversity.

\section{DisCussion}

We found that increasing either plant genotypic or species diversity led to quantitatively similar increases in primary production and that the plausible mechanisms responsible for these effects, niche complementarity or decreased intensity of competition, were also similar for each type of diversity. A recent meta-analysis of the effects of biodiversity on primary productivity found that the most diverse species assemblages had on average 1.7 times more biomass than monocultures 
(Cardinale et al. 2007). However, effect sizes ranged dramatically, and nearly $21 \%$ of studies showed negative to no effect of increasing diversity (Cardinale et al. 2007). The limited genotypic diversity literature also reports a wide range of increases in productivity across a diverse set of species: $\sim 0 \%$ in Poa pratensis (Vellend et al. 2010), $\sim 14 \%$ in Cakile edentula (Dudley and File 2007), $\sim 17 \%$ (Kotowska et al. 2010) and $\sim 69 \%$ (Crawford and Whitney 2010) in Arabidopsis thaliana, $\sim 36 \%$ in Solidago altissima (Crutsinger et al. 2006), $\sim 39 \%$ in Lupinus angustifolius (Milla et al. 2009), and $\sim 58 \%$ in Zostera marina (Reusch et al. 2005) (mean $=$ $33 \%$ ). Thus, the $17 \%$ increases in productivity that we observed at both levels of plant diversity were lower than average, but not atypical for genotypic or species diversity experiments. This variation among experiments, in addition to the comparison of vastly different experimental designs, highlights the importance of comparing the effects of genotypic and species diversity within a single field experiment, under similar conditions, and for the same duration of time.

Several factors may have contributed to the similar increases in plant productivity we observed with each type of diversity in this study. First, because the effect of species diversity on plant productivity generally increases with time (Cardinale et al. 2007), the similar effects of genotypic and species diversity that we observed may be a short-term phenomenon. Because plants comprising genotypic monocultures acquire resources very similarly, genotypic monocultures may become resource-limited more quickly than genotypic and/or species polycultures (where plants may differ in their patterns of resource utilization and thus may utilize a larger pool of resources). Resource limitation is believed to be a key mechanism of increased plant productivity in response to diversity (Hooper et al. 2005), and temporal variability in post-disturbance resource limitation along a continuum of plant genotypic to species diversity may be critical in predicting the effect size of increases in productivity. For example, a recent study investigating the effects of Solidago altissima genotypic diversity found that the standardized effect size of genotypic diversity on plant productivity over one growing season was similar to the effect size of species diversity from a multiyear experiment (Crutsinger et al. 2006). Understanding how trait variation and plant diversity interact temporally to affect ecosystem functioning represents an important gap in the literature, and we suggest that further studies are needed in this area of research.

A second factor that may have impacted our plant productivity results are the specific species selected for this experiment. Genotypic diversity-productivity relationships have only been investigated in a handful of species (Reusch et al. 2005, Crutsinger et al. 2006, Dudley and File 2007, Milla et al. 2009, Bischoff et al. 2010, Crawford and Whitney 2010, Kotowska et al. 2010). Some of these species are particularly abundant in their communities (i.e., dominant species), for example,

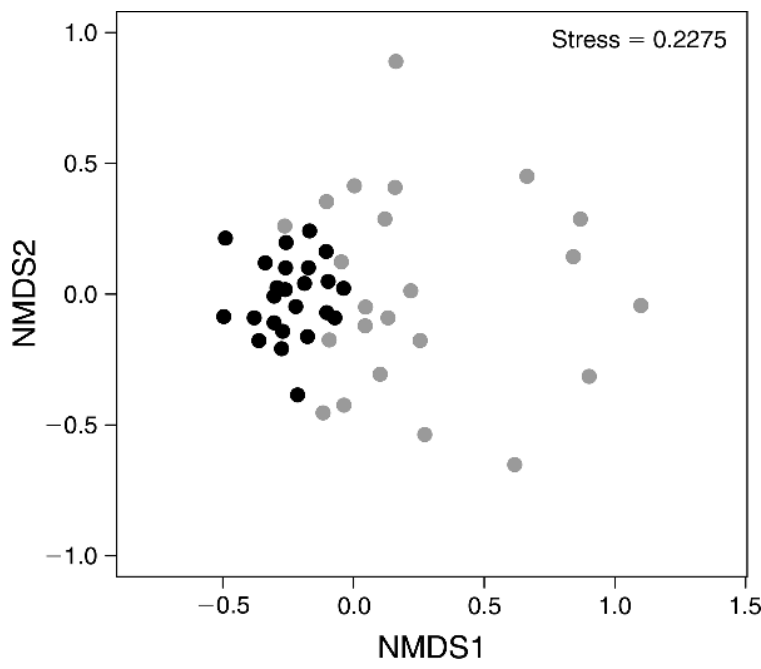

FIG. 3. Nonmetric multidimensional scaling (NMDS) ordination of arthropod communities on each common evening primrose (Oenothera biennis) genotype (black circles) and each old-field species (gray circles) obtained using two dimensions and 100 permutations. Each point represents the summed community of three monoculture plots of either an individual genotype or an individual species. Analysis of Bray-Curtis dissimilarity coefficients indicates that arthropod community assemblages are more dissimilar among species than among genotypes (nonparametric MANOVA, $R^{2}=0.13, F_{1,46}=6.78, P$ $<0.0001)$. Five hundred simulations on a random data set with identical parameters were used to verify that random stress $($ mean $=0.28)$ was significantly higher than model stress (mean $=0.23)$.

goldenrods (Solidago altissima [Crutsinger et al. 2006]) in old-field communities and eelgrass (Zostera marina [Reusch et al. 2005]) in coastal estuaries. Due to the myriad biotic and abiotic conditions experienced by dominant species, they may accumulate relatively large amounts of intraspecific trait variation, thus increasing the likelihood that the species will show a genotypic diversity-productivity effect. While O. biennis is not particularly dominant in old-field communities, it did respond positively to the growing conditions at our field site, producing the greatest amount of aboveground biomass of all species in our study (Fig. 1, Appendix C). It is possible that larger plants are more likely to manifest a diversity effect since they may more fully fill the available niche space, thus accentuating the importance of niche partitioning. An ideal future experiment, though logistically large, might simultaneously manipulate genotypic diversity in multiple different species with species diversity from a broad range of functional groups or phylogenetic distances.

A third possible mechanism for the similar increases in plant productivity we observed in this study may be that higher trophic levels are dampening the response of species polycultures and/or amplifying the response of genotypic polycultures. For example, in a separate experiment with $O$. biennis, levels of arthropod herbivory were $26 \%$ higher in genotypic monocultures 
compared to polycultures (S. H. McArt, unpublished data). If greater differences in herbivory occur between genotypic diversity treatments compared to those that occur between species diversity treatments, interactions with higher trophic levels may amplify the biomass increases observed with genotypic diversity. The contribution of herbivory to overyielding in plant diversity experiments has received some recent attention (e.g., Haddad et al. 2009, Parker et al. 2010), but has yet to be compared among different types of plant diversity.

Lastly, nonlinear declines in competition intensity with increasing genetic distance may explain the similar increases in plant productivity we observed in the genotypic and species diversity treatments. In other words, small changes in genetic distance among plants in genotypic monocultures vs. genotypic polycultures may reduce competition to the same degree as much larger changes in genetic distance among plants in species monocultures vs. species polycultures. Our data cannot distinguish among these multiple possibilities, yet each hypothesis is testable.

The second part of our study links arthropod community responses to each type of plant diversity. As expected, arthropod species richness responded less to plant genotypic diversity than species diversity (Fig. 2a). Interestingly, divergent mechanisms led to the increases in arthropod richness with each type of plant diversity (Figs. 2b-d, 3). Our data support the hypothesis that resource specialization influenced the arthropod response to plant species diversity while abundancedriven accumulation of species (more individuals hypothesis) influenced the arthropod response to plant genotypic diversity. These patterns fit the notion that insects are more likely to specialize on host plant species than host plant genotypes. However, resource specialization may be an important driver of arthropod responses to plant species hybrids and their backcrossed progeny (Dungey et al. 2000, Wimp et al. 2004, Evans et al. 2008), suggesting that comparing the similarity of arthropod communities (e.g., Fig. 3) across wider and more quantitative ranges of plant relatedness could greatly inform how plant genetics influences patterns of specialization and ultimately shapes arthropod community structure.

Overall, our results emphasize that diversity is inherently hierarchical and that within-species diversity may play a more important role in competitive interactions and community structure than previously realized. It is currently unclear whether the same factors causing declines in species diversity similarly impact genotypic diversity or whether these two levels of biodiversity are causally connected (Vellend 2005, Lankau 2009). Nonetheless, variation within species is inevitably lost before species themselves go extinct (Vitousek et al. 1997). Considering our results in relation to the long-standing focus on plant species diversity and ecosystem functioning (Chapin et al. 2000, Reich et al. 2001, Hooper et al. 2005, Tilman et al.
2006), we suggest that more emphasis be placed on conserving variation within species, elucidating the ecological consequences of genotypic diversity, and discerning how diversity among traits, relatedness, and trophic levels interact.

\section{ACKNOWLEDGMENTS}

S. C. Cook-Patton and S. H. McArt contributed equally to this work. We thank J. Simonis for assistance with R code for the ordination plot and analyses and E. R. Hoebeke for assistance with insect identifications. We thank M. Hunter, N. Gotelli, L. Oksanen, and R. Bingham for advice; M. Stastny, A. Hastings, A. Erwin, S. Campbell, S. Rasmann, B. Blossey, M. Geber, M. Weber, M. Johnson, M. Vellend, and several anonymous reviewers for manuscript critique; and M. KerschBecker, G. Petchenka, M. Stastny, C. Becker, S. Campbell, A. Erwin, P. Llambias, and numerous Cornell undergraduates for field assistance. The NSF (DEB- 0950231 to A. A. Agrawal and IGERT small grant in Biogeochemistry and Environmental Biocomplexity to S. H. McArt, S. C. Cook-Patton, and A. L. Parachnowitsch) and USDA-NRI (2006-35302-17431 to J. S. Thaler) supported this work.

\section{Literature Cited}

Barbosa, P., J. Hines, I. Kaplan, H. Martinson, A. Szczepaniec, and Z. Szendrei. 2009. Associational resistance and associational susceptibility: having right or wrong neighbors. Annual Review of Ecology, Evolution, and Systematics 40:1-20.

Bischoff, A., T. Steinger, and H. Müller-Schärer. 2010. The importance of plant provenance and genotypic diversity of seed material used for ecological restoration. Restoration Ecology 18:338-348.

Cadotte, M. W., J. Cavender-Bares, D. Tilman, and T. H. Oakley. 2009. Using phylogenetic, functional and trait diversity to understand patterns of plant community productivity. PLoS ONE 4:e5695.

Cardinale, B. J., J. P. Wright, M. W. Cadotte, I. T. Carroll, A. Hector, D. S. Srivastava, M. Loreau, and J. J. Weis. 2007. Impacts of plant diversity on biomass production increase through time because of species complementarity. Proceedings of the National Academy of Sciences USA 104:1812318128.

Chapin, F. S., et al. 2000. Consequences of changing biodiversity. Nature 405:234-242.

Cleland, R. E. 1972. Oenothera: cytogenetics and evolution. Academic Press, New York, New York, USA.

Crawford, K. M., and K. D. Whitney. 2010. Population genetic diversity influences colonization success. Molecular Ecology 19:1253-1263.

Crutsinger, G. M., M. D. Collins, J. A. Fordyce, Z. Gompert, C. C. Nice, and N. J. Sanders. 2006. Plant genotypic diversity predicts community structure and governs an ecosystem process. Science 313:966-968.

Dudley, S. A., and A. L. File. 2007. Kin recognition in an annual plant. Biology Letters 3:435-438.

Dungey, H. S., B. M. Potts, T. G. Whitham, and H. F. Li. 2000. Plant genetics affects arthropod community richness and composition: evidence from a synthetic eucalypt hybrid population. Evolution 54:1938-1946.

Evans, L. M., G. J. Allan, S. M. Shuster, S. A. Woolbright, and T. G. Whitham. 2008. Tree hybridization and genotypic variation drive cryptic speciation of a specialist mite herbivore. Evolution 62:3027-3040.

Gotelli, N. J., and G. L. Entsminger. 2006. Ecosim: null models software for ecology. Acquired Intelligence and Kesey-Bear, Jericho, Vermont, USA.

Gotelli, N. J., and G. R. Graves, editors. 1996. Null models in ecology. Smithsonian Institution, Washington, D.C., USA. 
Haddad, N. M., G. M. Crutsinger, K. Gross, J. Haarstad, J. M. H. Knops, and D. Tilman. 2009. Plant species loss decreases arthropod diversity and shifts trophic structure. Ecology Letters 12:1029-1039.

Hillebrand, H., and B. Matthiessen. 2009. Biodiversity in a complex world: consolidation and progress in functional biodiversity research. Ecology Letters 12:1405-1419.

Hooper, D. U., et al. 2005. Effects of biodiversity on ecosystem functioning: a consensus of current knowledge. Ecological Monographs 75:3-35.

Hughes, A. R., B. D. Inouye, M. T. J. Johnson, N. Underwood, and M. Vellend. 2008. Ecological consequences of genetic diversity. Ecology Letters 11:609-623.

Hutchinson, G. E. 1959. Homage to Santa-Rosalia or Why are there so many kinds of animals? American Naturalist 93:145159.

Johnson, M. T. J. 2007. Genotype-by-environment interactions lead to variable selection on life-history strategy in common evening primrose (Oenothera biennis). Journal of Evolutionary Biology 20:190-200.

Johnson, M. T. J., M. J. Lajeunesse, and A. A. Agrawal. 2006. Additive and interactive effects of plant genotypic diversity on arthropod communities and plant fitness. Ecology Letters 9:24-34.

Kotowska, A. M., J. F. Cahill, Jr., and B. A. Keddie. 2010. Plant genetic diversity yields increased plant productivity and herbivore performance. Journal of Ecology 98:237-245.

Lankau, R. A. 2009. Genetic variation promotes long-term coexistence of Brassica nigra and its competitors. American Naturalist 174:E40-E53.

Larson, E. L., S. M. Bogdanowicz, A. A. Agrawal, M. T. J. Johnson, and R. G. Harrison. 2008. Isolation and characterization of polymorphic microsatellite loci in common evening primrose (Oenothera biennis). Molecular Ecology Resources 8:434-436.

Levine, J. M. 2000. Species diversity and biological invasions: relating local process to community pattern. Science 288:852854.

Loreau, M., and A. Hector. 2001. Partitioning selection and complementarity in biodiversity experiments. Nature $412: 72$ 76.

McCune, B., and J. B. Grace, editors. 2002. Analysis of ecological communities. MjM Software Design, Gleneden Beach, Oregon, USA.

Milla, R., D. M. Forero, A. Escudero, and J. M. Iriondo. 2009. Growing with siblings: A common ground for cooperation or for fiercer competition among plants? Proceedings of the Royal Society B 276:2531-2540.

Oksanen, L., M. Sammul, and M. Magi. 2006. On the indices of plant-plant competition and their pitfalls. Oikos 112:149155.
Parker, J. D., J.-P. Salminen, and A. A. Agrawal. 2010. Herbivory enhances positive effects of plant genotypic diversity. Ecology Letters 13:553-563.

Petchey, O. L., A. Hector, and K. J. Gaston. 2004. How do different measures of functional diversity perform? Ecology 85:847-857.

Pimm, S. L., G. J. Russell, J. L. Gittleman, and T. M. Brooks. 1995. The future of biodiversity. Science 269:347-350.

Reich, P. B., et al. 2001. Plant diversity enhances ecosystem responses to elevated $\mathrm{CO}_{2}$ and nitrogen deposition. Nature 410:809-812.

Reusch, T. B. H., A. Ehlers, A. Haemmerli, and B. Worm. 2005. Ecosystem recovery after climatic extremes enhanced by genotypic diversity. Proceedings of the National Academy of Sciences USA 102:2826-2831.

Root, R. B. 1973. Organization of a plant-arthropod association in simple and diverse habitats: fauna of collards (Brassica oleracea). Ecological Monographs 43:95-120.

Schweitzer, J. A., J. K. Bailey, S. C. Hart, and T. G. Whitham. 2005. Nonadditive effects of mixing cottonwood genotypes on litter decomposition and nutrient dynamics. Ecology 86:2834-2840.

Srivastava, D. S., and J. H. Lawton. 1998. Why more productive sites have more species: an experimental test of the theory using tree-hole communities. American Naturalist 152:510-529.

Strong, D. R., J. H. Lawton, and R. Southwood. 1984. Insect on plants: community patterns and mechanisms. Harvard University Press, Cambridge, Massachusetts, USA.

Tilman, D., P. B. Reich, and J. M. Knops. 2006. Biodiversity and ecosystem stability in a decade-long grassland experiment. Nature 441:629-632.

Tilman, D., D. Wedin, and J. Knops. 1996. Productivity and sustainability influenced by biodiversity in grassland ecosystems. Nature 379:718-720.

Vellend, M. 2005. Species diversity and genetic diversity: parallel processes and correlated patterns. American Naturalist 166:199-215.

Vellend, M., E. B. M. Drummond, and H. Tomimatsu. 2010. Effects of genotype identity and diversity on the invasiveness and invasibility of plant populations. Oecologia 162:371-381.

Villeger, S., N. W. H. Mason, and D. Mouillot. 2008. New multidimensional functional diversity indices for a multifaceted framework in functional ecology. Ecology 89:22902301.

Vitousek, P. M., H. A. Mooney, J. Lubchenco, and J. M. Melillo. 1997. Human domination of Earth's ecosystems. Science 277:494-499.

Wimp, G. M., W. P. Young, S. A. Woolbright, G. D. Martinsen, P. Kelm, and T. G. Whitham. 2004. Conserving plant genetic diversity for dependent animal communities. Ecology Letters 7:776-780.

\section{APPENDIX A}

Responses of arthropod abundance and richness at individual trophic levels to plant genotypic and species diversity (Ecological Archives E092-077-A1).

\section{APPENDIX B}

Summary of life-history and performance characteristics for each plant species (Ecological Archives E092-077-A2).

\section{APPENDIX C}

Complementarity and selection effects for genotype and species polycultures excluding the focal plant from analyses (Ecological Archives E092-077-A3). 


\section{Ecological Archives E092-077-A1}

Susan C. Cook-Patton, Scott H. McArt, Amy L. Parachnowitsch, Jennifer S. Thaler, and Anurag A. Agrawal 2011. A direct comparison of the consequences of plant genotypic and species diversity on communities and ecosystem function. Ecology 92:915-923.

Appendix A (TABLE A1). Responses of arthropod abundance and richness to plant genotypic and species diversity. Results summarize two-way ANOVA and post-hoc independent contrasts. Significant results $(P<$ $0.05)$ are indicated in bold.

\begin{tabular}{|c|c|c|c|c|c|c|c|}
\hline Effect & Response & \multicolumn{2}{|c|}{ Whole model } & \multicolumn{2}{|c|}{ Plant species } & \multicolumn{2}{|c|}{ Plant genotypes } \\
\hline \multirow{11}{*}{ Diversity } & & $F$ & $P$ & $F$ & $P$ & $F$ & $P$ \\
\hline & Abundance & 12.45 & 0.001 & 0.52 & 0.473 & 18.46 & $<0.001$ \\
\hline & Predators & 18.62 & $<0.001$ & 19.67 & $<0.001$ & 2.24 & 0.136 \\
\hline & Omnivores & 8.40 & 0.004 & 0.02 & 0.898 & 18.12 & $<\mathbf{0 . 0 0 1}$ \\
\hline & Herbivores & 8.54 & 0.004 & 3.87 & 0.050 & 4.96 & 0.027 \\
\hline & Detritivores & 9.07 & 0.003 & 5.90 & 0.016 & 3.35 & 0.069 \\
\hline & Richness & 44.86 & $<0.001$ & 47.50 & $<0.001$ & 6.57 & 0.011 \\
\hline & Predators & 17.92 & $<0.001$ & 18.62 & $<0.001$ & 2.88 & 0.091 \\
\hline & Omnivores & 11.75 & 0.001 & 11.03 & 0.001 & 2.31 & 0.130 \\
\hline & Herbivores & 28.76 & $<0.001$ & 29.67 & $<0.001$ & 3.88 & 0.050 \\
\hline & Detritivores & 6.38 & 0.012 & 6.17 & 0.014 & 1.17 & 0.280 \\
\hline \multirow{11}{*}{$\begin{array}{c}\text { Level of } \\
\text { Relatedness }\end{array}$} & & \multicolumn{2}{|c|}{ Whole model } & \multicolumn{2}{|c|}{ Monoculture } & \multicolumn{2}{|c|}{ Polyculture } \\
\hline & Abundance & 85.77 & $<0.001$ & 22.44 & $<0.001$ & 70.44 & $<0.001$ \\
\hline & Predators & 0.42 & 0.516 & 3.73 & 0.055 & 1.07 & 0.302 \\
\hline & Omnivores & 86.89 & $<0.001$ & 19.14 & $<0.001$ & 78.26 & $<0.001$ \\
\hline & Herbivores & 36.04 & $<0.001$ & 16.77 & $<0.001$ & 19.35 & $<0.001$ \\
\hline & Detritivores & 5.73 & 0.018 & 3.96 & 0.048 & 1.94 & 0.165 \\
\hline & Richness & 2.45 & 0.119 & 10.72 & 0.001 & 1.20 & 0.274 \\
\hline & Predators & 0.26 & 0.608 & 2.81 & 0.095 & 0.95 & 0.332 \\
\hline & Omnivores & 11.92 & 0.001 & 11.09 & 0.001 & 2.37 & 0.125 \\
\hline & Herbivores & 1.18 & 0.278 & 0.97 & 0.326 & 6.51 & 0.011 \\
\hline & Detritivores & 12.22 & 0.001 & 9.97 & 0.002 & 3.15 & 0.077 \\
\hline Diversity & & \multicolumn{2}{|c|}{ Whole model } & & & & \\
\hline$\stackrel{x}{x}$ & Abundance & 6.30 & 0.013 & & & & \\
\hline & Predators & 4.42 & 0.037 & & & & \\
\hline
\end{tabular}




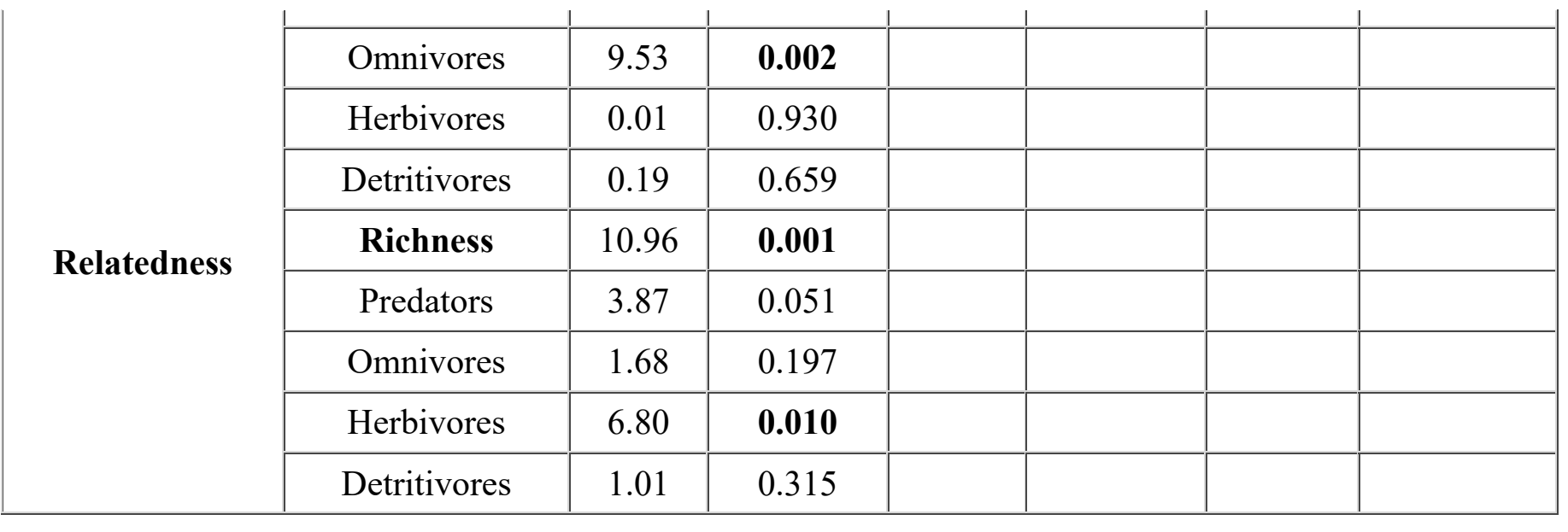




\section{Ecological Archives E092-077-A2}

Susan C. Cook-Patton, Scott H. McArt, Amy L. Parachnowitsch, Jennifer S. Thaler, and Anurag A. Agrawal 2011. A direct comparison of the consequences of plant genotypic and species diversity on communities and ecosystem function. Ecology 92:915-923.

Appendix B (TABLE B1). Information for species employed in this experiment. Life history information is denoted as $\mathrm{A}=$ annuals, $\mathrm{B}=$ biennials, and $\mathrm{P}=$ perennials, and derives from the USDA Plants Database (http://plants.usda.gov). Biomass data is the average mass across the experiment per species (mean biomass per individual \pm 1 s.e.m.).

* 24 distinct genotypes of Oenothera biennis were employed in the genotypic diversity manipulation. Seeds for other species were genetically mixed for the species diversity manipulations.

\begin{tabular}{|c|c|c|c|c|}
\hline Species & Family & Plant type & Life history & Average biomass \\
\hline Oenothera biennis* & Onagraceae & Forb & $\mathrm{AB}$ & $124.8 \pm 2.8$ \\
\hline Carex sp.1 & Cyperaceae & Graminoid & & $5.2 \pm 0.8$ \\
\hline Carex sp.2 & Cyperaceae & Graminoid & & $3.6 \pm 0.5$ \\
\hline Cichorium intybus & Asteraceae & Forb & BP & $37.9 \pm 6.3$ \\
\hline Daucus carota & Apiaceae & Forb & $\mathrm{AB}$ & $82.0 \pm 8.6$ \\
\hline Dianthus armeria & Caryophyllaceae & Forb & $\mathrm{AB}$ & $9.5 \pm 3.0$ \\
\hline Dipsacus sativus & Dipsacaceae & Forb & $\mathrm{AB}$ & $25.0 \pm 2.4$ \\
\hline Elymus repens & Poaceae & C3 grass & $\mathrm{P}$ & $7.0 \pm 0.7$ \\
\hline Epilobium parviflorum & Onagraceae & Forb & $\mathrm{P}$ & $27.5 \pm 12.2$ \\
\hline Galium mollugo & Rubiaceae & Forb & $\mathrm{P}$ & $25.0 \pm 1.9$ \\
\hline Leucanthemum vulgare & Asteraceae & Forb & $\mathrm{P}$ & $37.9 \pm 3.7$ \\
\hline Pastinaca sativa & Apiaceae & Forb & $\mathrm{BP}$ & $22.8 \pm 2.1$ \\
\hline Penstemon digitalis & Scrophulariaceae & Forb & $\mathrm{P}$ & $8.0 \pm 1.7$ \\
\hline Phleum pratense & Poaceae & C3 grass & $\mathrm{P}$ & $11.1 \pm 0.9$ \\
\hline Plantago lanceolata & Plantaginaceae & Forb & $\mathrm{ABP}$ & $46.1 \pm 3.2$ \\
\hline Rudbeckia hirta & Asteraceae & Forb & $\mathrm{ABP}$ & $57.5 \pm 5.1$ \\
\hline Rumex crispus & Polygonaceae & Forb & $\mathrm{P}$ & $21.7 \pm 2.8$ \\
\hline Saponaria officinalis & Caryophyllaceae & Forb & $\mathrm{P}$ & $13.5 \pm 1.6$ \\
\hline Silene vulgaris & Caryophyllaceae & Forb & $\mathrm{P}$ & $11.4 \pm 1.5$ \\
\hline Solidago altissima & Asteraceae & Forb & $\mathrm{P}$ & $47.9 \pm 4.9$ \\
\hline Symphyotrichum simplex & Asteraceae & Forb & $\mathrm{P}$ & $63.0 \pm 7.0$ \\
\hline Symphyotrichum lateriflorum & Asteraceae & Forb & $\mathrm{P}$ & $7.1 \pm 2.0$ \\
\hline
\end{tabular}




\begin{tabular}{|c|c|c|c|c|}
\hline Verbascum blattaria & Scrophulariaceae & Forb & B & $11.8 \pm 2.5$ \\
\hline Verbascum thapsus & Scrophulariaceae & Forb & B & $3.8 \pm 1.6$ \\
\hline Verbena hastata & Verbenaceae & Forb & BP & $50.1 \pm 3.4$ \\
\hline
\end{tabular}




\section{Ecological Archives E092-077-A3}

Susan C. Cook-Patton, Scott H. McArt, Amy L. Parachnowitsch, Jennifer S. Thaler, and Anurag A. Agrawal 2011. A direct comparison of the consequences of plant genotypic and species diversity on communities and ecosystem function. Ecology 92:915-923.

Appendix C (FIG. C1). Complementarity and selection effects for genotype polycultures (dark columns) and species polycultures (light columns) excluding the focal plant from analyses (means $\pm 95 \%$ confidence intervals).

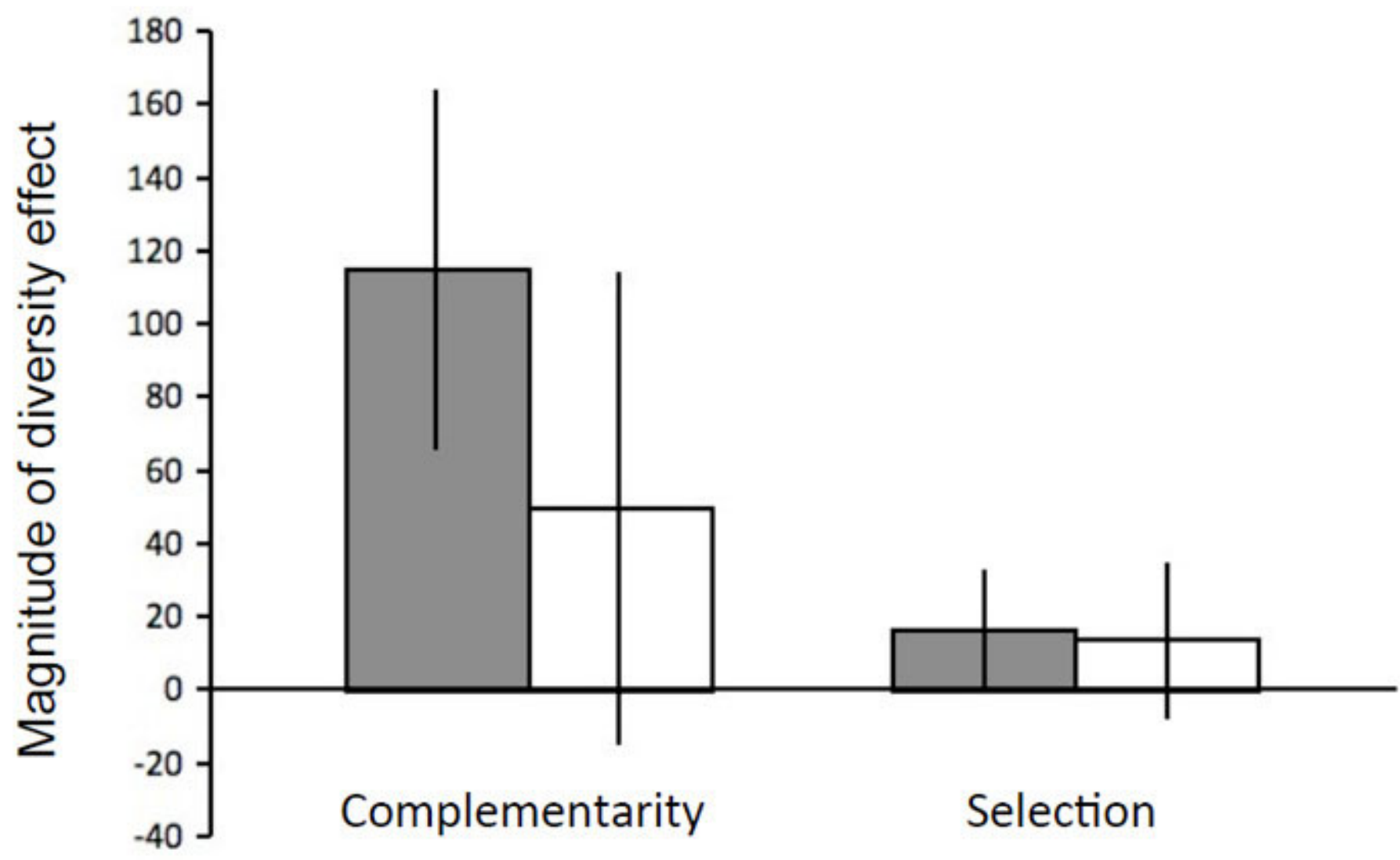

